\title{
Anti-inflammatory effect of patchouli alcohol isolated from Pogostemonis Herba in LPS-stimulated RAW264.7 macrophages
}

\author{
YAN-FANG XIAN ${ }^{1 *}$, YU-CUI LI ${ }^{2 *}$, SIU-PO IP ${ }^{1}$, ZHI-XIU LIN ${ }^{1}$, XIAO-PING LAI ${ }^{2}$ and ZI-REN SU ${ }^{2}$ \\ ${ }^{1}$ School of Chinese Medicine, The Chinese University of Hong Kong, Hong Kong SAR; \\ ${ }^{2}$ College of Chinese Medicines, Guangzhou University of Chinese Medicine, Guangzhou, P.R. China
}

Received December 2, 2010; Accepted February 21, 2011

DOI: 10.3892/etm.2011.233

\begin{abstract}
Pogostemonis Herba has long been used in traditional Chinese medicine for the treatment of inflammationrelated disorders. Patchouli alcohol (PA) isolated from Pogostemonis Herba is a tricyclic sesquiterpene that is known to exert a variety of pharmacological activities. The present study aimed to investigate the anti-inflammatory effect of PA on lipopolysaccharide (LPS)-stimulated RAW264.7 cells. Pre-treatment with PA at concentrations of 10,20 or $40 \mu \mathrm{M}$ dose-dependently decreased the production of tumor necrosis factor (TNF)- $\alpha$, interleukin (IL)-1 $\beta$, IL-6, nitric oxide (NO) and prostaglandin $\mathrm{E}_{2}$ in LPS-stimulated RAW264.7 cells. In addition, PA treatment also reversed the increased mRNA expression of TNF- $\alpha$, IL-1 $\beta$, IL-6, inducible nitric oxide synthase (iNOS) and cyclooxygenase (COX)-2 caused by LPS in RAW264.7 cells. These results indicate that PA is an important anti-inflammatory constituent of Pogostemonis Herba and that its anti-inflammatory effect may be mediated, at least in part, by down-regulation of the mRNA expression of a panel of inflammatory mediators, such as TNF- $\alpha$, IL-1 $\beta$, IL-6, iNOS and COX-2.
\end{abstract}

\section{Introduction}

Pogostemonis Herba is the dried aerial part of Pogostemon cablin (Blanco) Benth. (Labiatae), commonly known as 'Guang-Huo-Xiang' in Chinese or Cablin Patchouli in English. It has been traditionally used in Chinese medicine to remove dampness, relieve summer heat and exterior syndrome, and as an antiemetic and appetite stimulant (1). Pogostemonis Herba

Correspondence to: Dr Zhi-Xiu Lin, School of Chinese Medicine, The Chinese University of Hong Kong, Hong Kong SAR, P.R. China E-mail: linzx@cuhk.edu.hk

Dr Zi-Ren Su, College of Chinese Medicines, Guangzhou University of Chinese Medicine, Guangzhou, P.R. China

E-mail: suziren@gzhtcm.edu.cn

*Contributed equally

Key words: Pogostemonis Herba, patchouli alcohol, antiinflammatory effect, lipopolysaccharide, RAW264.7 macrophages is a common Chinese herb frequently used as a component in popular traditional formulae, such as Baoji Pill and Houdan Pill, for the treatment of inflammatory diseases (2,3). In addition, patchouli oil (essential oil of Patchouli) has been widely used in the cosmetic and oral hygiene industries to scent perfumes and flavor toothpaste. Recent research has demonstrated that patchouli oil has a variety of pharmacological activities, including antiemetic (4), anti-inflammatory $(3,5)$, anti-allergic (6), immunomodulatory (7) and antimicrobial actions (8). Chemically, it has been reported that Pogostemon cablin contains sesquiterpenes (9), cytotoxic chalcones (10) and antimutagenic flavones (11). Patchouli alcohol (PA; chemical structure in Fig. 1), a tricyclic sesquiterpene, is a major active ingredient of Pogostemonis Herba and is the most odorintensive component of patchouli oil (12). Pogostemonis Herba has been reported to contain $0.023-0.039 \%$ PA (12). In recent years, PA has attracted significant research attention due to its potential as a cognitive enhancing, learning impairment attenuating and neuroprotective agent $(13,14)$. However, it remains to be determined whether PA is the active constituent responsible for the anti-inflammatory effect of Pogostemonis Herba.

Macrophages are the first line of host defense against bacterial infection and cancer growth, and are believed to play essential roles in the initiation, maintenance and resolution of inflammation. When stimulated by bacterial endotoxin, such as lipopolysaccharide (LPS), macrophages produce a number of cytokines, such as tumor necrosis factor (TNF)- $\alpha$, interleukin (IL)-1 $\beta$ and IL-6; chemokines, such as prostaglandin $\mathrm{E}_{2}\left(\mathrm{PGE}_{2}\right)$ and nitric oxide (NO); inflammation-related enzymes, such as cyclooxygenase (COX)-2 and inducible nitric oxide synthase (iNOS) for the primary protection of the host $(15,16)$. These cytokines and chemokines are essential for the inflammatory response to pathogenic germs or toxicants (17). However, overproduction of these inflammatory mediators is associated with numerous diseases, such as rheumatoid arthritis and atherosclerosis (18-21). Thus, inhibition of the overproduction of these inflammatory mediators may have a beneficial effect on these inflammatory diseases.

RAW264.7, a mouse macrophage cell line, has been widely used as an in vitro inflammatory model $(15,22,23)$. In the present study, we aimed to investigate whether PA has an anti-inflammatory effect on LPS-stimulated RAW264.7 cells. We also examined the molecular mechanisms underlying the anti-inflammatory effect of PA by evaluating the mRNA 


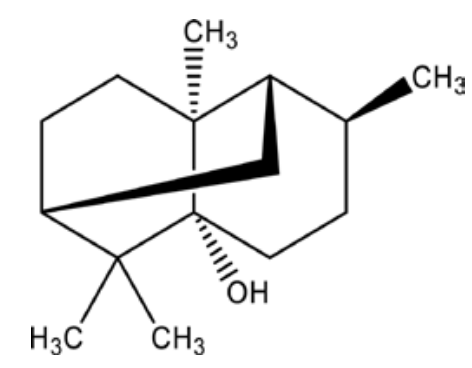

Figure 1. Chemical structure of patchouli alcohol.

expression of a number of inflammatory mediators, including TNF- $\alpha$, IL-1 $\beta$, IL-6, iNOS and COX-2.

\section{Materials and methods}

Plant materials and reagents. The aerial parts of Pogostemon cablin were collected in June 2009 in Maoming, Guangdong, China. The plant was authenticated by one of the authors (X.-P.L., experienced in pharmacognosy) at the College of Chinese Medicines, Guangzhou University of Chinese Medicine, where a voucher specimen (no. 090612) was deposited.

LPS, RPMI-1640 culture medium, sulfanilamide and N-1-naphthylethylenediamine dihydrocholide were purchased from Sigma-Aldrich (St. Louis, MO, USA). Fetal bovine serum (FBS), penicillin and streptomycin were purchased from Gibco (Grand Island, NY, USA). All other reagents and chemicals used in the study were of analytical grade.

Extraction and isolation of $P A$. The dried aerial parts of Pogostemon cablin $(5 \mathrm{~kg}$ ) were refluxed with $95 \%$ aqueous EtOH (40 liters x 2, 60 min each). The extract was evaporated under reduced pressure to obtain a residue (100 g). The residue was dissolved in acetone and subjected to silica gel column chromatography eluted with a petroleum ether-ethyl acetate-0.1\% formic acid (20:1:0.1, 9:1:0.1, 8:3:0.1 and 7:4:0.1) gradient elution system. The fraction eluted with petroleum ether-ethyl acetate-0.1\% formic acid (9:1:0.1) was combined and further evaporated to dryness, and a yellowish oily liquid was obtained. After crystallization from cyclohexane, white crystals of PA $(540 \mathrm{mg}$, yield $0.011 \%$ ) were finally obtained. The chemical structure of PA was identified by comparing its spectral data (MS, ${ }^{1} \mathrm{H}$ - and ${ }^{13} \mathrm{C}-\mathrm{NMR}$ ) to those published previously (24). The purity of PA was found to be $>98 \%$ based on gas chromatography (GC) analysis. PA was dissolved in dimethyl sulfoxide (DMSO) and the solvent concentration was $<0.1 \%$ DMSO in all experiments.

Cell culture and drug treatment. The RAW264.7 cell line, derived from murine macrophages, was obtained from the American Type Culture Collection (ATCC; Rockville, MD, USA). The cells were maintained in RPMI-1640 medium supplemented with $2 \mathrm{mM}$ glutamine, antibiotics $(100 \mathrm{U} / \mathrm{ml}$ penicillin and $100 \mathrm{U} / \mathrm{ml}$ streptomycin) and $10 \%$ heat-inactivated $\mathrm{FBS}$ at $37^{\circ} \mathrm{C}$ in a humidified atmosphere of $95 \%$ air and $5 \% \mathrm{CO}_{2}$. The cells were seeded onto 96-well culture plates at $5 \times 10^{4}$ cells/well, unless otherwise specified. After seeding for $24 \mathrm{~h}$, the cells were cultured in serum-free medium and incubated with different concentrations of PA (final concentrations:
$0,10,20$ and $40 \mu \mathrm{M}$ ) for $2 \mathrm{~h}$. LPS at a final concentration of $100 \mathrm{ng} / \mathrm{ml}$ was then added for an additional $24 \mathrm{~h}$.

Cell viability assay. Cell viability was measured by a CellTiter $96^{\circledR}$ AQueous One Solution Cell Proliferation assay (Promega, Madison, WI, USA). In brief, the cells were washed with D-Hank's solution after drug treatment. Then, $100 \mu \mathrm{l}$ of serum-free medium and $20 \mu \mathrm{l}$ of CellTiter 96 AQueous One Solution were added to each well. The cells were further incubated at $37^{\circ} \mathrm{C}$ for $1 \mathrm{~h}$. The quantity of formazan product, which is directly proportional to the number of living cells, was measured with a FLUOstar Optima microplate reader (BMG Labtech, Offenbury, Germany) at $490 \mathrm{~nm}$. Cell viability was expressed as a percentage of the non-treated control.

Nitrite oxide assay. The nitrite concentration in the culture medium was measured as an indicator of NO production according to the Griess reaction method described elsewhere (15). Briefly, the supernatants were collected at the end of the drug treatment. A total of $100 \mu l$ of each supernatant was mixed with the same volume of Griess reagent $(50 \mu \mathrm{l}$ $1 \%$ sulfanilamide in $5 \%$ phosphoric acid and $50 \mu \mathrm{l} 0.1 \%$ $\mathrm{N}$-1-naphthylethylenediamine dihydrocholide in water). After incubation for $10 \mathrm{~min}$ at room temperature, the absorbance was measured at $540 \mathrm{~nm}$ using a microplate reader. The content of nitrite was expressed as a percentage of the nontreated control.

$P G E_{2}$ assay. After PA treatment, the supernatants were collected and used for the $\mathrm{PGE}_{2}$ assay. The $\mathrm{PGE}_{2}$ concentration in the supernatant was determined using a commercially available $\mathrm{PGE}_{2}$ EIA kit (Cayman Chemical Co., Ann Arbor, MI, USA) according to the manufacturer's instructions. Briefly, $50 \mu \mathrm{l}$ of diluted standard/samples was added to a 96-well plate pre-coated with goat polyclonal anti-mouse IgG antibody. Aliquots of a $\mathrm{PGE}_{2}$ monoclonal antibody and $\mathrm{PGE}_{2}$ acetylcholine esterase (AChE) conjugate were added to each well and allowed to incubate at room temperature for $60 \mathrm{~min}$ on an orbital shaker. After washing five times with wash buffer containing 0.05\% Tween-20, $200 \mu \mathrm{l}$ of Ellman's reagent comprising acetylthiocholine and 5,5'-dithio-bis(2-nitrobenzoic acid) was added to the wells. The plates were then incubated for $60 \mathrm{~min}$ at room temperature in the dark, then the absorbance was read at $405 \mathrm{~nm}$ using a microplate reader. The content of $\mathrm{PGE}_{2}$ was expressed as a percentage of the non-treated control.

Cytokine determination. After PA treatment, the supernatants were collected and used for TNF- $\alpha$, IL- $1 \beta$ and IL- 6 assays. The levels of TNF- $\alpha$, IL- $1 \beta$ and IL- 6 in the supernatant were measured using commercially available sandwich enzymelinked immunosorbent assay (ELISA) kits (Invitrogen Co., Carlsbad, CA, USA) as per the manufacturer's instructions. Briefly, samples and biotinylated anti-TNF- $\alpha$, anti-IL-1 $\beta$ and anti-IL-6 antibodies (Biotin Conjugate) were respectively added to the 96-well plates pre-coated with monoclonal anti-mouse TNF- $\alpha$, anti-mouse IL- $1 \beta$ and anti-mouse IL-6 antibodies, and incubated for $90 \mathrm{~min}$ at room temperature, $90 \mathrm{~min}$ at $37^{\circ} \mathrm{C}$ and $2 \mathrm{~h}$ at room temperature, respectively. 


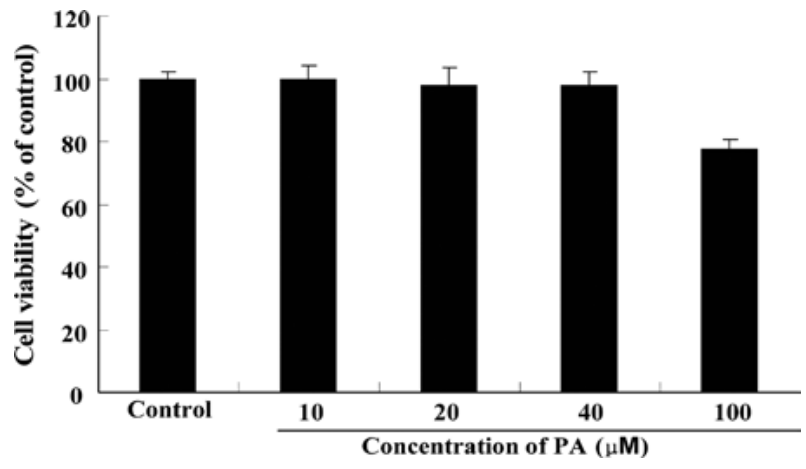

Figure 2. Effects of PA on the cell viability of RAW264.7 cells. The values shown represent the mean $\pm \operatorname{SEM}(n=6)$.

After washing four times, a streptavidin-HRP working solution was added and incubated for $30 \mathrm{~min}$ at room temperature. Then, tetramethylbenzidine (TMB) was added and incubated for $30 \mathrm{~min}$ at room temperature in the dark after washing. The reaction was stopped with stop solution and the absorbance was immediately recorded at $450 \mathrm{~nm}$. The levels of TNF- $\alpha$, IL-1 $\beta$ and IL- 6 were expressed as a percentage of the nontreated control.

Real-time PCR analysis. The RAW264.7 cells were seeded at $2 \times 10^{6}$ cells/well in 6 -well plates. The cells were washed twice with D-Hank's solution after PA treatment. Total RNA was isolated from the cells with TRIzol reagent (Gibco). The concentration of extracted RNA was measured spectrophotometrically at $260 \mathrm{~nm}$. The quality of RNA was assessed by the ratio of absorbance at 260 and $280 \mathrm{~nm}$. The values of A260/A280 from 1.9 to 2.1 were considered acceptable. Total RNA $(1.5 \mu \mathrm{g})$ was used to synthesize cDNA using the High capacity cDNA reverse transcription kit (Applied Biosystems, Foster City, CA, USA) following the manufacturer's instructions. Real-time PCR was performed with a Taq Man fast universal PCR master mix kit (2X) (Applied Biosystems) and mouse Taq Man gene expression assays were conducted (Applied Biosystems; assay ID: TNF- $\alpha$, Mm00443258_m1; IL-6, Mm99999064_m1; IL-1ß, Mm00434228_m1; COX-2, Mm01307330_g1; iNOS, Mm00440488_m1 and $\beta$-actin, Mn02619580_g1). The reactions were run at $50^{\circ} \mathrm{C}$ for $2 \mathrm{~min}$ and $95^{\circ} \mathrm{C}$ for $10 \mathrm{~min}$, followed by 60 cycles at $95^{\circ} \mathrm{C}$ for $15 \mathrm{sec}$ and $60^{\circ} \mathrm{C}$ for $1 \mathrm{~min}$ on the Applied Biosystems Step-One Fast Real-Time PCR system. Sequence Detection Software 2.0 (Applied Biosystems) was used for data analysis. The relative expression of TNF- $\alpha$, IL-1 $\beta$, IL- 6, COX- 2 and iNOS mRNA was normalized to the amount of $\beta$-actin in the same cDNA using the relative quantification $2^{-\Delta \Delta C t}$ method (25). The fold change in target gene cDNA relative to the $\beta$-actin internal control was determined using the following formula: Fold change $=2^{-\Delta \Delta \mathrm{Ct}}$, where $\Delta \Delta \mathrm{Ct}=\left(\mathrm{Ct}_{\text {target gene }}-\mathrm{Ct}_{\beta \text {-actin }}\right)-\left(\mathrm{Ct}_{\text {control }}-\mathrm{Ct}_{\beta \text {-actin }}\right)$.

Statistical analysis. Data were expressed as the mean \pm SEM. Multiple group comparisons were performed using one-way analysis of variance (ANOVA) followed by Dunnett's test to detect differences between different treatment groups and the control. Differences were considered statistically significant at $\mathrm{p}<0.05$.

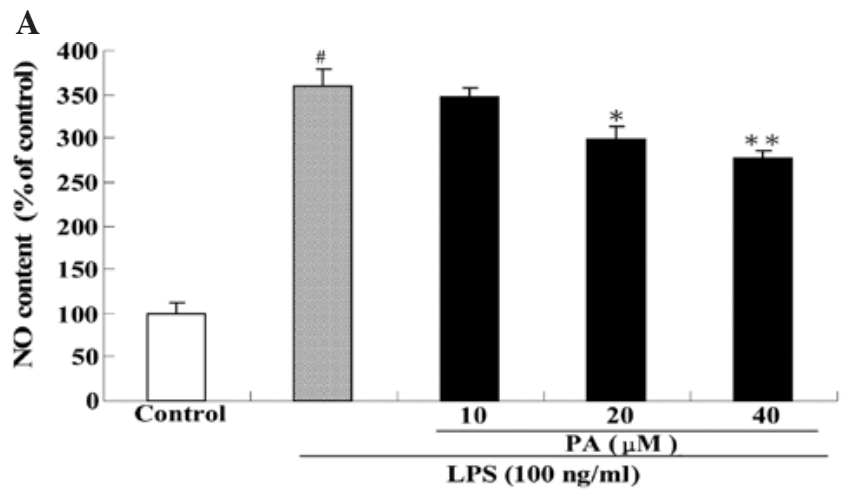

B

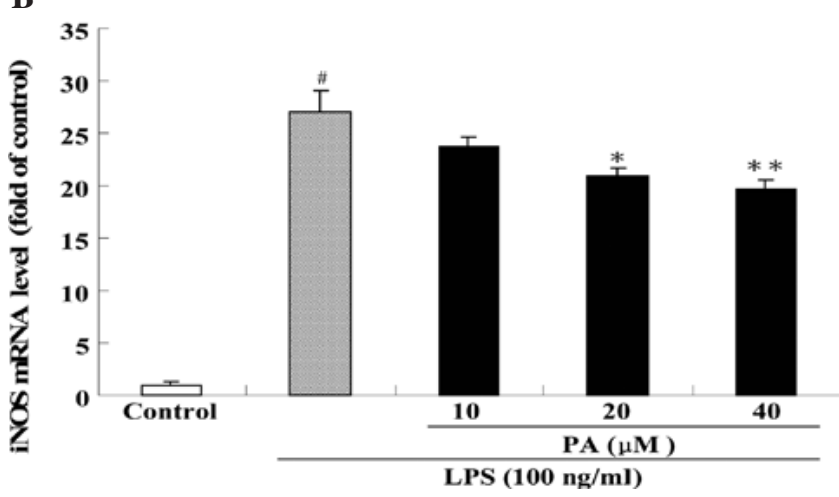

Figure 3. Effects of PA on the production of NO (A) and mRNA expression of iNOS (B) in LPS-stimulated RAW264.7 cells. The values shown represent the mean \pm SEM $(n=3-6) .{ }^{*} \mathrm{p}<0.01$ compared to the control group; ${ }^{*} \mathrm{p}<0.05$, ${ }^{* *} \mathrm{p}<0.01$ and ${ }^{* * * *} \mathrm{p}<0.01$ compared to the LPS group.

\section{Results}

Cytotoxicity of PA on RAW264.7 cells. As shown in Fig. 2, $\mathrm{PA}$ at concentrations up to $40 \mu \mathrm{M}$ did not show significant cytotoxicity to RAW264.7 cells when incubated for $24 \mathrm{~h}$.

Effect of PA on NO production and iNOS mRNA expression in LPS-stimulated RAW264.7 cells. Fig. 3 shows the effect of PA on NO production (A) and iNOS mRNA expression (B) in LPS-stimulated RAW264.7 cells. After exposure of RAW264.7 cells to $100 \mathrm{ng} / \mathrm{ml}$ LPS for $24 \mathrm{~h}$, the production of NO and the mRNA expression of iNOS were significantly increased by 3.6- and 27-fold, respectively, as compared to the control group. Pre-treatment with 20 and $40 \mu \mathrm{M}$ PA significantly decreased the production of NO by 17 and $23 \%$, respectively, as compared to the LPS group. Pre-treatment with 20 and $40 \mu \mathrm{M}$ PA also significantly suppressed the mRNA expression of iNOS by 23 and $28 \%$, respectively, as compared to the LPS group.

Effect of PA on $P G E_{2}$ production and COX-2 mRNA expression in LPS-stimulated RAW264.7 cells. Fig. 4 shows the effect of PA treatment on $\mathrm{PGE}_{2}$ production (A) and COX-2 mRNA expression (B) in LPS-stimulated RAW264.7 cells. After exposure of RAW264.7 cells to $100 \mathrm{ng} / \mathrm{ml}$ LPS for $24 \mathrm{~h}$, the production of $\mathrm{PGE}_{2}$ and the mRNA expression of COX-2 were significantly increased by 39 - and 180 -fold, respectively, as compared to the control group. Pre-treatment with 20 and $40 \mu \mathrm{M}$ PA significantly decreased the production of $\mathrm{PGE}_{2}$ by 19 and $21 \%$, respectively, as compared to the LPS group. In 


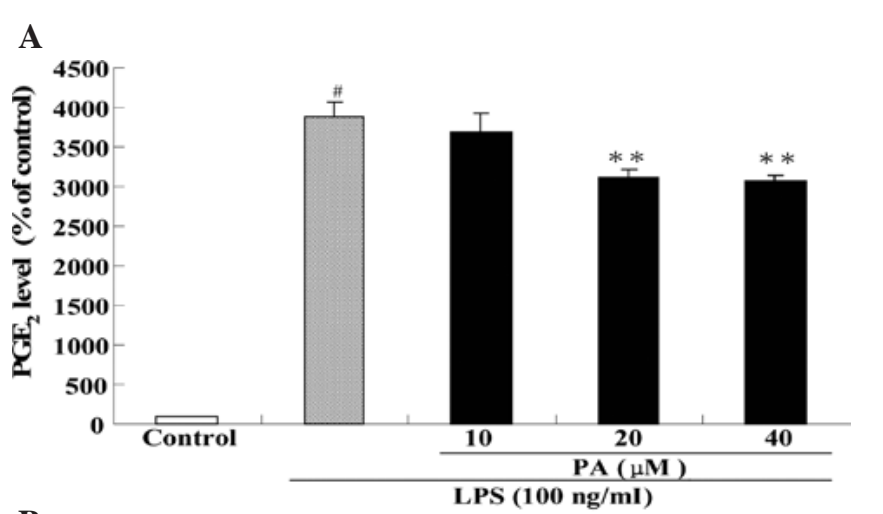

B

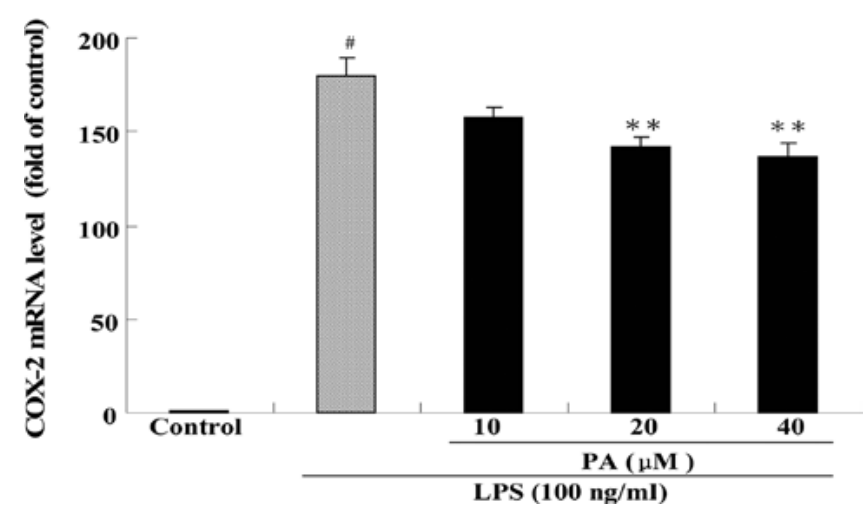

Figure 4. Effects of PA on the production of $\mathrm{PGE}_{2}$ (A) and mRNA expression of COX-2 (B) in LPS-stimulated RAW264.7 cells. The values shown represent the mean \pm SEM $(n=3-6) . "{ }^{\#}<<0.01$ compared to the control group; ${ }^{*} \mathrm{p}<0.05$ and ${ }^{* *} \mathrm{p}<0.01$ compared to the LPS group.

addition, pre-treatment with 20 and $40 \mu \mathrm{M}$ PA also significantly decreased the mRNA expression of COX-2 by 21 and $24 \%$, respectively, as compared to the LPS group.

Effect of PA on pro-inflammatory cytokine production and mRNA expression in LPS-stimulated RAW264.7 cells. Fig. 5 shows the effect of PA treatment on the protein levels of TNF- $\alpha$ (A), IL-1 $\beta$ (B) and IL-6 (C) in LPS-stimulated RAW264.7 cells. After exposure of RAW264.7 cells to $100 \mathrm{ng} / \mathrm{ml}$ LPS for $24 \mathrm{~h}$, the protein levels of TNF- $\alpha$, IL-1 $\beta$ and IL-6 were significantly increased by $8-, 8$ - and 20 -fold, respectively, as compared to the control group. Pre-treatment with 10, 20 and $40 \mu \mathrm{M}$ PA dose-dependently suppressed the protein level of TNF- $\alpha$ by 15,17 and $23 \%$, respectively, as compared to the LPS group. In a similar fashion, pre-treatment with 10, 20 and $40 \mu \mathrm{M}$ PA dose-dependently decreased the protein level of IL-1 $\beta$ by 17,23 and $25 \%$, respectively, as compared to the LPS group. In addition, pre-treatment with 20 and $40 \mu \mathrm{M}$ PA also significantly reduced the protein level of IL- 6 by 17 and $35 \%$, respectively, as compared to the LPS group. Consistent with the results of the protein levels, real-time PCR revealed that pre-treatment with PA also significantly inhibited the mRNA expression of TNF- $\alpha$, IL-1 $\beta$ and IL-6 in LPS-stimulated RAW264.7 cells (Fig. 6).

\section{Discussion}

The present study clearly demonstrated that treatment of RAW264.7 cells with LPS caused a significant increase in
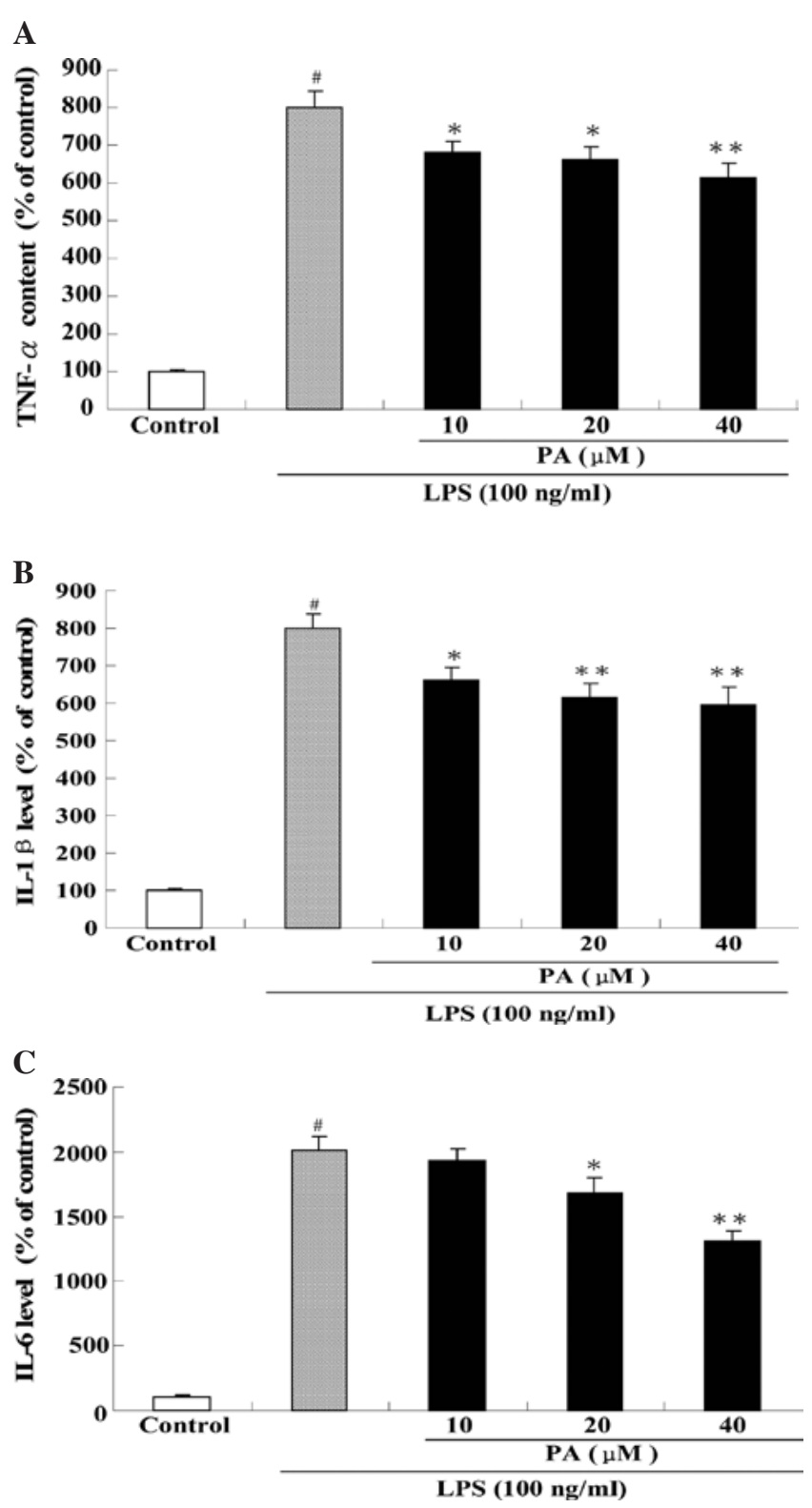

Figure 5. Effects of PA on the production of TNF- $\alpha$ (A), IL-6 (B) and IL-1 $\beta$ (C) in LPS-stimulated RAW264.7 cells. The values shown represent the mean \pm SEM $(n=6) . " ~ p<0.01$ compared to the control group; ${ }^{*} \mathrm{p}<0.05$ and ${ }^{* *} \mathrm{p}<0.01$ compared to the LPS group.

the protein and mRNA levels of iNOS, COX-2, TNF- $\alpha$, IL-6 and IL-1 $\beta$. However, pre-treatment with PA at concentrations of 10, 20 and $40 \mu \mathrm{M}$ dose-dependently decreased the protein and mRNA levels of NO, $\mathrm{PGE}_{2}, \mathrm{TNF}-\alpha$ and IL- $1 \beta$ in LPS-stimulated RAW264.7 cells.

$\mathrm{NO}$, an important messenger molecule, is intimately involved in the inflammatory response $(26,27)$. NO is generated by a family of enzymes called NO synthase (NOS) (28). It is known that NO plays a beneficial role in anti-tumor and anti-virus replication, and in anti-inflammatory processes $(29,30)$. However, overproduction of NO by macrophages has been implicated in bacterial septic shock (31), and in certain inflammatory and autoimmune diseases $(32,33)$. For this reason, down-regulation of the overproduction of NO has become a new therapeutic strategy for the treatment of chronic inflammatory diseases $(34,35)$. In the present study, we found 


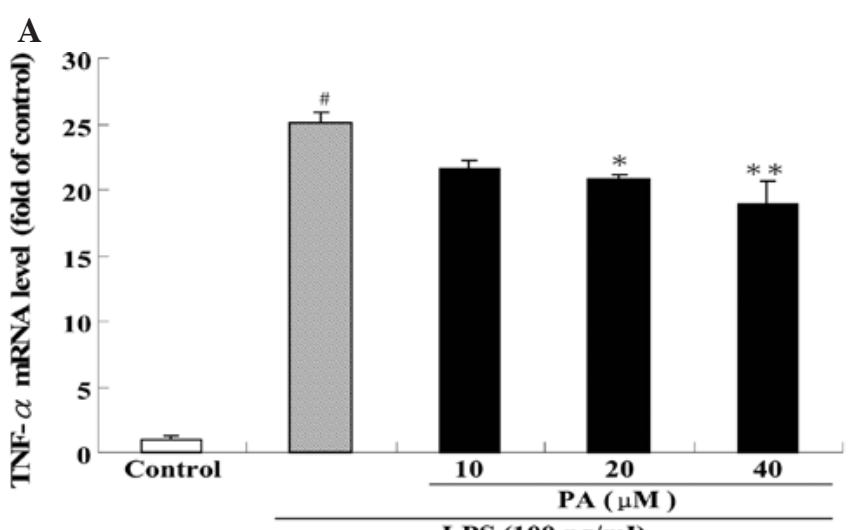

B

LPS (100 ng/mI)
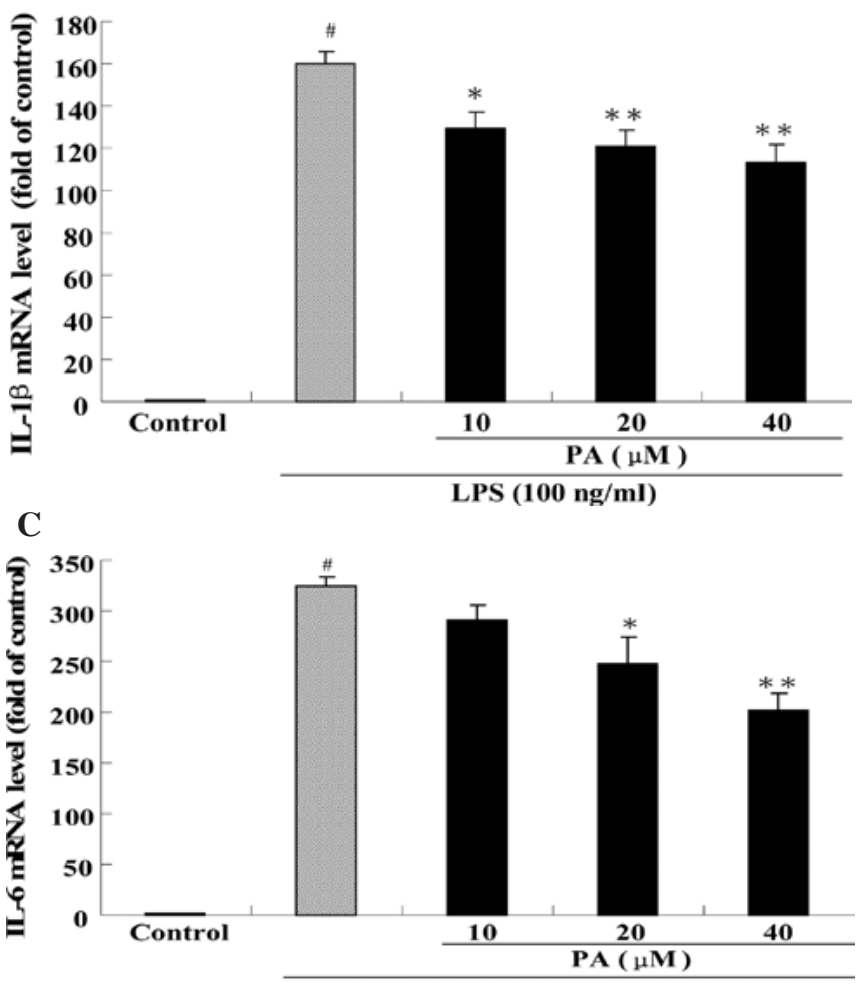

LPS $(100 \mathrm{ng} / \mathrm{ml})$

Figure 6. Effects of PA on the mRNA expression of TNF- $\alpha$ (A), IL-6 (B) and IL-1 $\beta$ (C) in LPS-stimulated RAW264.7 cells. The values shown represent the mean \pm SEM $(n=3) .{ }^{*} p<0.01$ compared to the control group; ${ }^{*} p<0.05$ and *** $\mathrm{p}<0.01$ compared to the LPS group.

that exposure of RAW264.7 cells to LPS caused a significant increase in NO production and iNOS mRNA expression. This observation is consistent with the findings previously reported by other researchers $(15,36)$. Pre-treatment with PA markedly reduced NO production and iNOS mRNA expression in LPS-stimulated RAW264.7 cells, suggesting that PA is capable of exerting anti-inflammatory action by inhibiting iNOS mRNA expression.

$\mathrm{PGE}_{2}$ is considered to be one of the most potent inflammatory mediators in the inflammatory response and plays a major role in the pathogenesis of various inflammatory diseases, edema, angiogenesis, tumor growth and invasion $(15,37) . \mathrm{PGE}_{2}$ is transformed from arachidonic acid via a COX-2 catalytic reaction (38). COX-2 has been demonstrated to be a critical pro-inflammatory enzyme which contributes to the development of many chronic inflammatory diseases, such as vascular atherosclerosis and rheumatoid arthritis (39). Recent years have seen an increasing interest in the use of COX-2 inhibitors as novel anti-inflammatory agents. Indeed, non-steroidal anti-inflammatory drugs (NSAIDs) exert their antipyretic, anti-inflammatory and analgesic effects through the inhibition of COX activity and the reduction of the production of inflammatory mediators, such as $\mathrm{PGE}_{2}$ (15). Our present study demonstrated that $\mathrm{PGE}_{2}$ production and $\mathrm{COX}-2$ mRNA expression were markedly increased in LPS-stimulated RAW264.7 cells. However, pre-treatment with PA significantly mitigated the augmented $\mathrm{PGE}_{2}$ production and COX-2 mRNA expression in these cells. These results suggest that PA exhibits a selective inhibitory effect on COX-2 similar to traditional NSAIDs. Thus, PA is worthy of further development as a new anti-inflammatory agent.

Cytokines play important roles in the regulation of inflammation. TNF- $\alpha$, IL-1 $\beta$ and IL- 6 are multifunctional proinflammatory cytokines and exhibit various pro-inflammatory effects in chronic inflammatory diseases, such as rheumatoid arthritis and atherosclerosis (40-42). TNF- $\alpha$ has long been considered as a key mediator for the induction of apoptosis and the development of the humoral immune response. At a high concentration, however, it elicits detrimental effects, such as causing tissue injury and potentiating septic shock $(43,44)$. It has been reported that TNF- $\alpha$ elicits downstream pro-inflammatory events, such as the release of IL-6, another inflammatory cytokine (45). IL-6 plays essential roles in host defense, acute phase reactions, immune responses and nerve cell functions (46-49). A high level of IL-6 has been observed in various pathological conditions, including bacterial and viral infections, trauma, autoimmune diseases and inflammations $(47,48)$. IL-1 $\beta$ is mainly produced by macrophages, monocytes and $\mathrm{T}$ cells and is also involved in immune defense against infection. In the present study, we clearly demonstrated that the protein and mRNA levels of TNF- $\alpha$, IL-1 $\beta$ and IL- 6 were significantly increased in LPS-stimulated RAW264.7 cells, and pre-treatment with PA dose-dependently reduced the protein and mRNA levels of TNF- $\alpha$, IL-1 $\beta$ and IL- 6 in these cells. These findings indicate that the anti-inflammatory effect of PA is associated with the down-regulation of the mRNA expression of TNF- $\alpha$, IL-1 $\beta$ and IL-6.

In conclusion, the present experimental results demonstrated that PA exerts an anti-inflammatory effect on LPS-stimulated RAW264.7 cells. The observed anti-inflammatory action of PA may be mediated, at least in part, by down-regulation of the mRNA expression of TNF- $\alpha$, IL-1 $\beta$, IL-6, iNOS and COX-2 in LPS-stimulated RAW264.7 cells. These promising experimental findings not only justify the use of Pogostemonis Herba in Chinese medicine for inflammatory conditions, but also suggest that PA, an essential active constituent of Pogostemonis Herba, to be a potential chemical agent for the treatment of inflammatory diseases. Further investigation to elucidate the underlying mechanism of action associated with the anti-inflammatory effect of PA is currently in progress at our laboratory.

\section{Acknowledgements}

This study was supported by a grant from the National Natural Science Foundation of China (project no. u0732004). 


\section{References}

1. Chinese Pharmacopoeia Committee: Pharmacopoeia of China Chinese Medical Science and Technology Press, Beijing, 2010.

2. Zhang D, Xiao LY, Cheng YW, Li HL, Feng ZM, Lin PY, Wu WY and Huang KR: Pharmacological action of Baoji Pill. Tradit Chin Drug Res Clin Pharmacol 9: 212-214, 1998.

3. Xian YF, Suo J, Huang XD, Hou SZ, Chen JN, Ye MR and Su ZR: A pharmacological study on anti-inflammatory effects of refined Huodan recipe. Chin J Exp Tradit Med Formul 13: 54-56, 2007.

4. Yang Y, Kinoshita K, Koyama K, Takahashi K, Tai T, Nunoura Y and Watanabe K: Anti-emetic principles of Pogostemon cablin (Blanco) Benth. Phytomedicine 6: 89-93, 1999.

5. Zhao SC, Jia Q and Liao FL: The anti-inflammatory and analgesic pharmacological study of Patchouli extract. Chin Tradit Pat Med 29: 285-287, 2007.

6. Suo J, Xian YF, Huang XD, Hou SZ, Chen JN, Ye MR and Su ZR: A pharmacological study on the anti-allergy effects of refined Houdan recipe. Chin J Exp Tradit Med Formul 13: 47-49, 2007.

7. Qi SS, Hu LP, Chen WN, Sun HB and Ma XD: Immunological regulation effects of essential oil in leaves of Cablin Patchouli herbal on mice. Chin Arch Tradit Chin Med 27: 774-776, 2009.

8. Liu XR, Fan R, Zhang YY and Zhu MJ: Study on antimicrobial activities of extracts from Pogestemon cablin (Blanco) Benth. Food Sci Technol 24: 220-227, 2009.

9. Yang D, Chaumont JP and Millet J: Antifungal activity of the essential oils from Agastache rugosa and Pogostemon cablin against dermatophytes and opportunistic fungi. Zhongguo Yao Xue Za Zhi 35: 9-11, 2000.

10. Park EJ, Park HR, Lee JS and Kim J: Licochalcone A: an inducer of cell differentiation and cytotoxic agent from Pogostemon cablin. Planta Med 64: 464-466, 1998.

11. Miyazawa M, Okuno Y, Nakamura S and Kosaka H: Suppression of the furylfuramide-induced SOS response by monoterpenoids with a p-menthane skeleton using the Salmonella typhimurium TA1535/pSK1002 Umu test. J Agric Food Chem 48: 642-647, 2000.

12. Zhao ZZ, Lu J, Leung K, Chan CL and Jiang ZH: Determination of patchoulic alcohol in herba Pogostemonis by GC-MS-MS. Chem Pharm Bull 53: 856-860, 2005.

13. Huang XW, Bai L, Xu FH and Wu YJ: Inhibitory activities of patchouli alcohol on neurotoxicity of $\beta$-amyloid peptide. Jie Fang Jun Yi Xue Za Zhi 24: 338-340, 2008.

14. Huang XW, Liu RT and Lü QJ: Patchouli alcohol on memory impairment induced by scopolamine learning and memory function in mice. Zhong Yao Cai 40: 1431-1433, 2009.

15. Hu XD, Yang Y, Zhong XG, Zhang XH, Zhang YN, Zheng ZP, Zhou Y, Tang W, Wang YF, Hu LH and Zuo JP: Antiinflammatory effects of Z23 on LPS-induced inflammatory responses in RAW264.7 macrophages. J Ethnopharmacol 120: 447-451, 2008.

16. Tao JY, Zheng GH, Zhao L, Wu JG, Zhang XY, Zhang SL, Huang ZJ, Xiong FL and Li CM: Anti-inflammatory effects of ethyl acetate fraction from Melilotus suaveolens Ledeb on LPS-stimulated RAW264.7 cells. J Ethnopharmacol 123: 97-105, 2009.

17. Liew FY: The role of innate cytokines in inflammatory response. Immunol Lett 85: 131-134, 2003.

18. Bertolini A, Ottani A and Sandrini M: Selective COX-2 inhibitors and dual acting anti-inflammatory drugs: critical remarks. Curr Med Chem 9: 1033-1043, 2002.

19. Isomaki $P$ and Punnone J: Pro and anti-inflammatory cytokines in rheumatoid arthritis. Ann Med 29: 499-507, 1997.

20. Korhonen R, Lathi A, Kankaanranta $\mathrm{H}$ and Moilanen E: Nitric oxide production and signaling in inflammation. Curr Drug Targets Inflamm Allergy 4: 471-479, 2005.

21. Libby P, Aikawa M and Schönbeck U: Cholesterol and atherosclerosis. Biochim Biophys Acta 1529: 299-309, 2000.

22. Shin EM, Zhou HY, Guo LY, Kim JA, Lee SH, Merfort I, Kang SS, Kim HS, Kim S and Kim YS: Anti-inflammatory effects of glycyrol isolated from Glycyrrhiza uralensis in LPS-stimulated RAW264.7 macrophages. Int Immunopharmacol 8: 1524-1532, 2008.

23. Jeong GS, Lee DS and Kim YC: Cudratricus xanthone A from Cudrania tricuspidata suppresses pro-inflammatory mediators through expression of anti-inflammatory heme oxygenase- 1 in RAW264.7 macrophages. Int Immunopharmacol 9: 241-246, 2009

24. Guan L, Quan LH, Xu LZ and Cong PZ: Chemical constituents of Pogostemon cablin (Blanco) Benth. Zhongguo Zhong Yao Za Zhi 19: 355-356, 1994.
25. Livak KJ and Schmittgen TD: Analysis of relative gene expression data using real-time quantitative PCR and the 2(-Delta Delta C(T)) Method. Methods 25: 402-408, 2001

26. Zhang XJ, Li Y, Tai GX, Xu GY, Zhang PY, Yang Y, Lao FX and Liu ZH: Effects of activin A on the activities of mouse peritoneal macrophages. Cell Mol Immunol 2: 63-67, 2005.

27. Gayathri B, Manjula N, Vinaykumar KS, Lakshmi BS and Balakrishnan A: Pure compound from Boswellia serrata extract exhibits anti-inflammatory property in human PBMCs and mouse macrophages through inhibition of TNF $\alpha$, IL-1 $\beta, \mathrm{NO}$ and MAP kinases. Int Immunopharmacol 7: 473-482, 2007.

28. Palmer RM, Rees DD, Ashton DS and Moncada S: L-arginine is the physiological precursor for the formation of nitric oxide in endothelium-dependent relaxation. Biochem Biophys Res Commun 153: 1251-1256, 1988.

29. Schmidt HH and Walter U: NO at work. Cell 78: 919-925, 1994.

30. MacMicking J, Xie QW and Nathan C: Nitric oxide and macrophage function. Annu Rev Immunol 15: 323-350, 1997.

31. Petros A, Bennett D and Vallance P: Effect of nitric oxide synthase inhibitors on hypotension in patients with septic shock. Lancet 338: 1557-1558, 1991.

32. McCartney-Francis N, Allen JB, Mizel DE, Albina JE, Xie QW Nathan CF and Wahl SM: Suppression of arthritis by an inhibitor of nitric oxide synthase. J Exp Med 178: 749-754, 1993.

33. Kleemann R, Rothe H, Kolb-Bachofen V, Xie QW, Nathan C, Martin S and Kolb H: Transcription and translation of inducible nitric oxide synthase in the pancreas of prediabetic $\mathrm{BB}$ rats. FEBS Lett 328: 9-12, 1993.

34. Hobbs AJ, Higgs A and Moncada S: Inhibition of nitric oxide synthase as a potential therapeutic target. Annu Rev Pharmacol Toxicol 39: 191-220, 1999.

35. Pacher P, Joseph S, Beckman JS and Liaudet L: Nitric oxide and peroxynitrite in health and disease. Physiol Rev 87: 315-424, 2007.

36. Lin QY, Jin LJ, Cao ZH and Xu YP: Inhibition of inducible nitric oxide synthase by Acanthopanax senticosus extract in RAW264.7 macrophages. J Ethnopharmacol 118: 231-236, 2008.

37. Claria J: Cyclooxygenase-2 biology. Curr Pharma Des 9: 2177-2190, 2003.

38. Rocca B and FitzGerald GA: Cyclooxygenases and prostaglandins: shaping up the immune response. Int Immunopharmacol 2: 603-630, 2002.

39. Seibert K, Zhang Y, Leahy K, Hauser S, Masferrer J, Perkins W, Lee L and Isakson P: Pharmacological and biochemical demonstration of the role of cyclooxygenase 2 in inflammation and pain. Proc Natl Acad Sci USA 91: 12013-12017, 1994.

40. Bondeson J: The mechanisms of action of disease-modifying antirheumatic drugs: a review with emphasis on macrophage signal transduction and the induction of proinflammatory cytokines. Gen Pharmacol 29: 127-150, 1997.

41. Andreakos E, Foxwell B and Feldmann M: Is targeting Toll-like receptors and their signaling pathway a useful therapeutic approach to modulating cytokine-driven inflammation? Immunol Rev 202: 250-265, 2004.

42. Dayer JM: The process of identifying and understanding cytokines: from basic studies to treating rheumatic diseases. Best Pract Res Clin Rheumatol 18: 31-45, 2004.

43. Shohami E, Ginis I and Hallenbeck JM: Dual role of tumor necrosis factor alpha in brain injury. Cytokine Growth Factor Rev 10: 119-130, 1999.

44. Yoon HJ, Moon ME, Park HS, Im SY and Kim YH: Chitosan oligosaccharide (COS) inhibits LPS-induced inflammatory effects in RAW 264.7 macrophage cells. Biochem Biophys Res Commun 358: 954-959, 2007.

45. Straub RH, Linde DN, Mannel J, Scholmerich W and Falk A: A bacteria-induced switch of sympathetic effect or mechanisms augments local inhibition of TNF- $\alpha$ and IL- 6 secretion in the spleen. FASEB J 14: 1380-1388, 2000.

46. Hibi M, Nakajima K and Hirano T: IL-6 cytokine family and signal transduction: a model of the cytokine system. J Mol Med 74: 1-12, 1996.

47. Hirano T, Matsuda T and Nakajima K: Signal transduction through gp130 that is shared among the receptors for the interleukin 6 related cytokine subfamily. Stem Cells 12: 262-277, 1994.

48. Van Snick J: Interleukin-6: an overview. Annu Rev Immunol 8: 253-278, 1990.

49. Taga T and Kishimoto T: Gp130 and the interleukin-6 family of cytokines. Annu Rev Immunol 15: 797-819, 1997. 